\title{
Assessing the Impact of Social Media Analytics Software on Student Learning
}

\author{
Keith Massie \\ Kutztown University of Pennsylvania \\ Moe Folk \\ Kutztown University of Pennsylvania
}

\begin{abstract}
This article examines differences between two courses tasked with writing a technical report on social media content. In one course, students employed any freely available applications to aid their analysis. In another course, students were provided access to commercial social media analytics software (SMAS). Using grounded theory and statistical methods, the researchers found clear differences among groups. $t$ tests were employed on a number of group variables to determine statistical significance. Effect size was calculated and found to be consistently high. Overall, students who had access to social media analytics software (SMAS) demonstrated stronger overall analytical skills than their counterparts.
\end{abstract}

Keywords: Social Media, Social Media Assessment, Writing Assessment, Software, Report Writing, Social Media Analytic

\section{INTRODUCTION}

As the varieties of digital content continue to expand, universities struggle to keep up in the hopes of engaging current realities and adapting to emerging ones in order to provide students with the critical digital composing and analytical skills needed to navigate their post-university economic, civic, and personal lives successfully. Social media is just one example. Worldwide, the number of active social media users increased from 970 million in 2010 to 1.96 billion in 2015, and the total number of global users now stands at 3 billion people, or $45 \%$ of the world's population ('Continued Growth', 2016). Despite that tremendous growth, the number of academic programs devoted to social media study worldwide has not blossomed, even though the gap between what the marketplace desires in terms of student abilities and the skills with which students arrive at university is large, opening the door for universities to close the gap. Students may be more 'tethered' to technology than ever before (Turkle, 2011), but they often fail to have the deep, applicable technology skills desired by employers; for instance, students spend countless hours engaging social media but often demonstrate little acumen for analyzing the connections and patterns across social media platforms. In short, more research is needed that addresses how to bridge the gulf between the abilities students have and the types of skills necessary for them to thrive in social media environments in a way that not only appeals to potential employers, but are also increasingly necessary for cultivating an engaged citizenship and developing meaningful interpersonal relationships. 
As part of an ongoing effort to develop curriculum that addresses the gap in students' existing and desired digital skills, the researchers developed a minor in digital communication and new media that includes coursework in social media studies such as social media analytics. The minor has student outcomes related to developing digital analysis and production, particularly students' ability to synthesize and analyze digital information such as social media content. Because of the amount of social media content generated daily and the importance of tracking the effects of social media content in real time, a number of software options ranging from freeware to commercially licensed programs exist to aid researchers. The objective of this study was to determine whether access to social media analytics software (in particular, a commercial software option) aided the development of students' digital analysis and report writing skills. The goals of the initial assessment were the following:

- To determine the level of digital analytical skill that students possess without exposure to dedicated analytics software

- To determine the effect of dedicated analytics software on developing students' ability to generate, evaluate, and analyze digital information via qualitative methods

- To determine the effect of dedicated analytics software on developing students' ability to generate, evaluate, and analyze digital information via quantitative methods

By examining the results of a common assignment given by two different instructors across two different courses, the researchers have determined that commercial software does indeed show promise. When commercial software is employed, students appear to better hone a number of significant skills (e.g., analytical and quantitative skills). Traditional analysis (such as that employed in many literature classes) often relied on qualitative efforts, and technical reports (such as that employed in many technical writing classes) often incorporated quantitative analysis, but the necessity in keeping up with the immediacy and impact of social media content necessitates both qualitative and quantitative approaches. Moreover, the ability to track network effects such as reach and spread in real time often necessitates social media analytics software (i.e., without such software, it is too time intensive to be effective).

The initial results point to the efficacy of commercial social media analytics software (SMAS) in advancing digital analysis and report writing. The results suggest that students who have access to social media analytics software increase the quality and quantity of their reports focused on a social media phenomenon, as well as dive more deeply into analytic patterns that exist within the data. This assessment is only the initial step in examining the utility, practicality, and benefit of employing social media analytics software for the analysis of social media phenomena. Clearly, more research about such new technology is needed, and this article is an initial entry into better understanding the pedagogical impact of using social media analytics software to advance student learning.

\section{LITERATURE REVIEW}

While numerous academic studies have addressed the assessment of various digital genres, the existing academic literature specifically related to social media is scant. For example, within the larger umbrella of digital content, a significant body of work has addressed the assessment of various genres such as digital portfolios (e.g., Lorenzo and Ittelson, 2005; Woodward and Nanlohy, 2010; Yancey, McElroy, and Powers, 2013; Zanzucchi and Truong, 2013); digital writing (Yancey, 2004; McKee and DeVoss, 2013; Moran and Herrington, 2013; Poe, 2013; Hicks 2015); new media writing (Penrod, 2005; Ball, 2006; Sorapure, 2006; VanKooten, 2013); and multimodal composition (Anderson et al., 2006; Borton and Huot, 2007; Shipka, 2009; Murray, Sheets, and Williams, 2010; Katz and Odell, 2012; Adsanatham, 2012; National Writing Project MAP Group, 2013). On the other hand, academic assessment literature specifically tied to social media is currently lacking, although Jain et al. (2012), who assessed the use of a social software blog space called Trading Room, argued their study provided 'empirical evidence of the efficacy of blogs and social media in higher education, in particular in finance' (702). However, the work of Jain et al. is primarily concerned with blogging and business courses instead of the role of contemporary social media platforms and analytics programs in writing and communication 
courses. In addition, Chai, Potdar, and Dillon (2009) assessed social media; however, their work did not focus on employing social media software pedagogically. Rather, their study examined 19 existing frameworks for assessing the quality of social media content itself.

\section{METHODOLOGY}

The assessment examined a common assignment across two different courses. The two courses included a Digital Rhetoric and Writing course (Fall 2015) and a New Media and Communication course (Spring 2016). The assignment required students to examine a distinct social media phenomenon (e.g., a hashtag, Twitter handle, Facebook account, or business/personal accounts across various online platforms). The two courses, however, differed in the resources available to students. In the Fall 2015 course, students used any freely available online applications for analyzing their respective social media phenomenon. In contrast, students in the Spring 2016 course were granted access to commercially available social media analytics software. Students within both courses combined their findings, evaluation, and analysis into a final technical report describing the overall composition of the social media phenomenon, as well as any important patterns or trends that took place within the assignment's time period. The final reports of Fall 2015 students who lacked access to the software $(n=20)$ were compared to the final reports of the Spring 2016 students who had access $(n=26)$.

Investigators constructed an assessment instrument that appropriated elements of the AACU VALUE rubrics for quantitative and critical analysis. The instrument design focused primarily on analytical development and depth, but it also examined basic features within the final report. Basic features examined within the assessment included word count and the number of embedded images used as evidence. Examining word count, one can see whether the use of social media analytics software increased or decreased the size of a technical report. In addition, image usage in reports was divided into SMAS and non-SMAS images as students could screen capture data visualization in the SMAS application (if they had access) and/or any other online image. The outcome of this measure could suggest the extent that students are inhibited or encouraged to employ visual rhetoric into their final reports.

In addition to measuring basic features such as word and image count, the instrument employed five questions on a Likert-type scale. A summary of each question's focus follows:

1) Does the report provide sufficient context for the given topic?

2) Does the report employ a range of rhetorical strategies?

3) Does the report engage a significant amount of quantitative data?

4) What is the overall quality of the analysis of quantitative data?

5) What is the overall quality of the report?

To begin, all student names were removed from the reports as to limit potential bias, and investigators randomly sampled two reports from each course. These four reports (i.e., 2 non-SMAS and 2 SMAS) were used as means for norming the coding process. After independent review, coders met to compare coding outcomes. Simple intercoder reliability was high; however, coders did need to address differences in coding. Coders applied a grounded theory approach (Glaser and Strauss, 1967). The open coding process continued after norming until researchers found they needed to recalibrate the coding due to a nuance found in later reports. Using the constant comparative method of grounded theory, coders solidified the evaluation parameters. After recalibration, researchers returned to prior reports that had already been coded to verify that it had no effect on their outcome. Each coder worked independently, and the open coding process continued until all final reports were coded. Coders shared outcomes and began to analyze the data.

After generating the data set, investigators employed a standard t-test to evaluate the differences between group means (i.e., non-SMAS versus SMAS report) to determine if said differences were statistically significant. The data analysis tool add-on for Excel was used to calculate the t-test outcome. 


\section{RESULTS}

The assessment led to eight (8) distinct results. These results include: (1) word count, (2) number of images employed, (3) number of non-SMAS images employed, (4) development of context within report, (5) range of rhetorical strategies within report, (6) amount of quantitative data evaluated in report, (7) depth of quantitative analysis in report, and (8) overall qualitative and quantitative depth in report. The various results can be categorized into three sets: (1) textual and/or visual tasks done by the student, (2) quantitative tasks, and (3) overall depth.

\section{Textual/Visual Tasks}

In completing the specific, course assignment, students were instructed to not only develop a technical report about a given online phenomenon but also to integrate images as evidence of their assertions. While it does not provide insight into the quality of said reports, one can assess the length of such reports generically via word count.

For this study, word count included all text within the report with the exception of the title and any bibliography. The number of words used by the SMAS group $(M=2422, S D=957)$ was larger than the number of words employed by the non-SMAS group $(M=1723, S D=836)$. This difference was statistically significant, $t(44)=2.59, \mathrm{p}<.05$. Cohen's $\mathrm{d}$ was calculated $(d=0.78)$ and was found to exceed Cohen's (1988) convention for a moderate effect size $(d=0.50)$ and nears his convention for a large effect size $(d=0.80)$. In general, this outcome suggests that students who had access to SMAS wrote significantly longer reports than those without access. One can also examine the difference in the two groups use of images as a means of support to claims explicated in the reports.

Unlike the way many instructors approach traditional reports, the researchers encouraged students to incorporate images into their social media analysis. Images were used as evidence of a given feature of the analysis. For this study, total images included all images located within the text regardless of whether the given image was captured through the SMAS or not. The total number of images employed within SMAS group reports $(M=21, S D=11)$ was greater than those by non-SMAS group reports $(M=15, S D$ $=8)$. This difference was statistically significant, $t(44)=2.08, \mathrm{p}<.05$. Cohen's $\mathrm{d}$ was calculated $(d=$ $0.62)$ and was found to exceed Cohen's (1988) convention for a moderate effect size $(d=0.50)$. Here, it appears that students with access to SMAS provided more visual evidence overall than their peers in the non-SMAS group.

Within the set of all images used in a given report, one can also examine how many images were included from non-SMAS sources. Such images could be located by both groups being analyzed. The number of non-SMAS images employed within SMAS group reports $(M=8, S D=5)$ was less than those by non-SMAS group reports $(M=15, S D=9)$. This difference was statistically significant, $t(44)=3.26, \mathrm{p}$ $<.05$. Cohen's $d$ was calculated $(d=0.96)$ and was found to exceed Cohen's (1988) convention for a large effect size $(d=0.80)$. Such a finding suggests that students in the SMAS group may have been dependent on the visualizations provided within the SMAS rather than seek out additional visual evidence to support their claims. In addition to providing visual evidence in support of their assertions, students were asked to provide context regarding the specific online phenomenon that they were analyzing.

Question 1 of the assessment instrument focused on the quality of the report's ability to develop context for the reader of the report. The quality of context development for SMAS group reports $(M=$ $3.4, S D=0.76)$ was similar to non-SMAS group reports $(M=3.2, S D=1)$. This difference was not statistically significant, $t(44)=0.86, \mathrm{p}=\mathrm{ns}$. Such a finding suggests that the use of SMAS neither aided nor detracted from students' ability to establish context within their reports. Having provided context, students needed to employ rhetorical strategies - ranging from appeal to experts to emotional appeals--to make their case within the report.

Question 2 of the assessment instrument focused on the range of rhetorical strategies used within the report. The range of rhetorical strategies for the SMAS group $(M=2.6, S D=0.86)$ was less than those by non-SMAS group reports $(M=3.1, S D=0.91)$. This difference was statistically significant, $t(44)=2.00$, $\mathrm{p}<.05$. Cohen's d was calculated $(d=0.57)$ and was found to exceed Cohen's (1988) convention for a 
moderate effect size $(d=0.50)$. This finding suggests that students in the SMAS group may have become so dependent on the SMAS for data that they focused less attention on presenting the data rhetorically.

\section{Quantitative Tasks}

In addition to the writing and visual components of the report assignment, students were also asked to analyze their given topics data. One can assess both the amount of the data analyzed as well as the depth to which it was examined.

Question 3 of the assessment instrument focused on the amount of quantitative data evaluated within the report. The amount of quantitative data evaluated for the SMAS group $(M=3.4, S D=0.75)$ was greater than the amount by non-SMAS group reports $(M=1.4, S D=0.88)$. This difference was statistically significant, $t(44)=8.47, \mathrm{p}<.001$. Cohen's $\mathrm{d}$ was calculated $(d=2.45)$ and was found to exceed both Cohen's (1988) convention for a large effect size $(d=0.80)$ as well as Rosenthal's (1996) classification of 'very large' $(d=1.30)$. It appears that the SMAS group gained significantly due to the software's ability to generated data. In addition to the amount of data examined, one can also assess how the two groups differed regarding the depth of the analysis.

Question 4 of the assessment instrument focused on the analysis of quantitative data within the report. The analysis of quantitative data for the SMAS group $(M=2.7, S D=1)$ was greater than the amount by non-SMAS group reports $(M=1.4, S D=1.1)$. This difference was statistically significant, $t(44)=4.29, \mathrm{p}$ $<.001$. Cohen's d was calculated $(d=1.24)$ and was found to exceed Cohen's (1988) convention for a large effect size $(d=0.80)$ and nears Rosenthal's (1996) classification of 'very large' $(d=1.30)$. Such a finding suggests that the SMAS group benefited from having greater access to data - as to locate patterns and connections between and amount elements - than the non-SMAS group.

\section{Overall Analytical Depth}

Evaluating overall analytical depth, one can examine the qualitative elements in conjunction with the qualitative ones to compare the two groups. Question 5 of the assessment instrument focused on the overall analytical depth of qualitative and quantitative information within the report. The analytical depth for the SMAS group $(M=2.77, S D=0.85)$ was greater than the amount by non-SMAS group reports $(M$ $=2.45, S D=0.69$ ). This difference suggests statistical significant, $t(44)=1.36, \mathrm{p}<.10$. Given this finding, it appears that while the SMAS group gained in specific, aforementioned ways, the SMAS group was not statistically significant for producing better overall reports.

\section{DISCUSSION}

The results suggest that a number of positive outcomes arise from students having access to the social media analytics software (SMAS). One can examine and interpret the results of each element of the instrument as to better understand the impact that SMAS has on students' ability to analyze and report patterns within and across a social media phenomenon.

Students with access to SMAS wrote reports that incorporated significantly more words. On the surface, one may suspect this outcome since SMAS generates more information from which students can compose their report. However, this interpretation may be suspect because it is a superficial reading of the outcome. Both non-SMAS and SMAS students had a plethora of information available to them because they were free to scour the Internet for pertinent information. Thus, while there is clearly a statistically significant difference between the two groups regarding the word count of their final reports, it is unclear as to the reason for this difference.

Similar to the difference in word count, one finds that students in the SMAS group employed more images in their reports than the non-SMAS group. This finding is likely due to the fact that data visualization within SMAS added a source of visual representation that was unavailable to the non-SMAS group. One could argue that engaging the visualization of data regularly through their use of SMAS, students in the SMAS group developed a propensity for visual evidence and incorporated it more than their counterparts who did not use SMAS. Combining images from SMAS along with other 
representations, the SMAS group used statistically more images; however, if we examine the use of nonSMAS images (which both groups had equal access to), we find a significant difference.

Students in the non-SMAS group employed more non-SMAS images than students in the SMAS group. When examining images within the reports, one finds depictions that do not originate in the SMAS software were much more common in the non-SMAS group. The non-SMAS group averaged 13 images, but the SMAS group only average 8 non-SMAS images. Part of this difference may be due to the (over)use of SMAS images by those in the SMAS group, as students averaged 13 SMAS images per report.

Since the SMAS social media analytics software does not provide context for information generated while using it, one would not expect it to aid in developing context for a given topic of a report. The data suggests that neither the SMAS group nor the non-SMAS group is statistically different regarding context development.

Comparing the SMAS group to the non-SMAS group, one sees a statistical difference regarding the range of rhetorical strategies. The non-SMAS group employed a wider range of rhetorical strategies (e.g., rhetorical questions) within their text. One reason for this outcome may be that the SMAS group had to spend increased energy on the development of SMAS data and its quantitative analysis; the non-SMAS group could focus energy on the development of qualitative factors and rhetorical strategies because such reports had little quantitative data with which to evaluate and analyze.

The SMAS group had a statistically significant greater amount of quantitative data, as well as depth of quantitative analysis, than the non-SMAS group. The statistical significance of these findings is at the $99.9 \%$ confidence level. This outcome is likely expected because SMAS provided a significant array of quantitative data that was unavailable to those without access to SMAS. Moreover, the amount of data generated by SMAS allows for comparisons and contrasts, as well as cross tabulations, correlations, and other statistical tools. Nonetheless, some students in the non-SMAS group did seek out free online social media analytics software, but the capabilities of the freeware did not result in significant amounts of data.

The difference between SMAS and non-SMAS groups in the overall qualitative and quantitative analytical depth of their reports is statistically significant above the $80 \%$ confidence level. Overall, the SMAS group has higher averages for their overall qualitative and quantitative analytical depth. This outcome is likely expected since the SMAS software adds information that is unavailable to non-SMAS users; however, the SMAS group could still use any content located outside of the SMAS software.

In summary, reports written after employing SMAS social media analytics software exhibit numerous differences compared to non-SMAS reports. The SMAS group reports (1) were longer, (2) employed more images, (3) had greater amounts of quantitative data, (4) had more depth in their quantitative analysis, and (5) appeared to have overall better qualitative and quantitative analytical depth. In fact, no non-SMAS report achieved the highest score possible on question 5 (the measure of overall quality), which indicates there is, in effect, a glass ceiling for digital analysis that arises for students who lack access to the significant amounts of data that can be generated by commercial social media analytics software.

\section{Limitations}

Because this was an initial attempt at assessing the effect of social media analytics software and scholarship on assessing social media in general is itself quite limited, there are a number of limitations to this study, and the impact of each on the results is unknown.

As with most research, the sample size is potentially too small. With a small sample $(\mathrm{n}=46)$ split across 2 conditions, one wonders how generalizable the results are to the population as a whole. Future research would likely need to generate a larger sample as to increase the strength of the findings.

In addition to a small sample, the researchers failed to track demographic data. The research lacks the ability to ascertain if any particular social group (e.g., women) had distinctly difference outcomes. In the future, research should make certain to track demographic data such as age, sex, race, and academic year as to look for internal patterns within the sample. 
As the study focuses on an area that has had little research and almost no educational assessment, there were no instruments available to easily measure the variables. The choice to design an instrument that appropriated aspects of the VALUE rubric was one done from necessity. Since the instrument has never been tested for validity or reliability, little can be known regarding its accuracy. It does, however, appear to have face validity.

\section{Suggestions for Future Research}

Social media is a dynamic and growing field of study. Research regarding its effectiveness for business is becoming more common; however, little research addresses the use of social media as a pedagogical end or means, and no research has assessed the use of social media analytics software on student report writing. This article provides initial insights into students using social media analytics software, and there are a number of ways to further develop this line of inquiry. The following are some suggestions to help this area develop further.

One way that future research could expand this work is by tracking demographics. Do sophomores with access to social media analytics software write better reports than seniors who lack such resources? Do male or female users of social media analytics software write better reports? A number of similar questions could be asked that examine how a given demographic group engages and performs regarding the employment of social media analytics software.

Future research should consider seeking an answer to "Why do users of SMAS write longer reports than non-SMAS users?' While a superficial rationale would suggest that they have more content to work with, such an assertion seems weak. Both non-SMAS and SMAS users had an infinite supply of information via the Internet. What it is about using social media analytics software that encourages lengthier compositions?

The current project looked at the number of images within non-SMAS and SMAS reports. One item that was not examined is how student incorporated visual evidence that they themselves constructed. For example, non-SMAS users appear to more readily construct a pie chart or bar graph to represent their data; however, SMAS users, possibly complacent because of the visualization of data in the application, almost never construct and organize data visually. Future research should examine this potential trend and the affect it may have on a report's ethos relative to audience.

Overall, more research should focus on assessing social media use in educational settings. Some recent research has assessed using technology or social media as a delivery method for teaching the content of a given course (Jain et al., 2012). However, what happens when the course actually focuses on social media analysis, social media content creation, and similar digital content? More assessment is needed of courses that employ social media not as a means to some other end but as an end in itself, particularly as it relates to developing students' critical thinking, analytical, and composing skills in digital environments. 


\section{REFERENCES}

Adsanatham, C. (2012). Integrating Assessment and Instruction: Using Student-generated Grading Criteria to Evaluate Multimodal Digital Projects. Computers and Composition, 29, 152-174.

Anderson, D., Atkins, A., Ball, C., Homicz Millar, K., Selfe, C., \& Selfe, R. (2006). Integrating Multimodality into Composition Curricula: Survey Methodology and Results from a CCCC Research Grant. Composition Studies, 34(2), 59-84.

Ball, C. (2006). Designerly $\neq$ Readerly: Re-assessing Multimodal and New Media Rubrics for Use in Writing Studies. Convergence, 12(4), 393-412.

Blair, D., DeVoss, N., Hochman, W., Jimerson, L., Jurich, C., Murphy, S., Rupert, B., Whithaus, C., \& Wood, J. In Digital Writing Assessment and Evaluation, edited by Heidi A. McKee and Dànielle Nicole DeVoss. Computers \& Composition Digital Press. Retrieved July 7, 2016, from http://ccdigitalpress.org/dwae/07_nwp.html.

Borton, S., \& Huot, B. (2007). Responding and Assessing. In Multimodal Composition: Resources for Teachers, edited by Cynthia Selfe and Pamela Takayoshi, 1-14. Cresskill, NJ: Hampton Press.

Chai, K., Potdar, V., \& Dillon, T. (2009). Content Quality Assessment Related Frameworks for Social Media. Computational Science and its Applications - ICCSA 2009, 5593, 791-805. "The Continued Growth of Social Media." 2016. Search Engine Journal, January. Retrieved from https://www.searchenginejournal.com/growth-social-media-v-3-0-infographic/155115/

Cohen, J. (1988). Statistical Power Analysis for the Behavioral Sciences, 2nd ed. Hillsdale, NJ: Erlbaum.

DeVoss, N. (n.d.). Computers \& Composition Digital Press. Retrieved July 12, 2016, from http://ccdigitalpress.org/dwae/09_vankooten.html.

Glaser, B., \& Strauss, A. (1967). The Discovery of Grounded Theory: Strategies for Qualitative Research. Chicago: Aldine Publishing Company.

Hicks, T. (2015). Assessing Students' Digital Writing: Protocols for Looking Closely. New York: Teachers College Press.

Jain, A., Thomson, D., Farley, A., \& Mulready, P. (2012). Engagement and Learning Through Social Software in Finance: A Retrospective on the Trading Room Experience. Assessment \& Evaluation in Higher Education, 37(6), 701-718.

Katz, S. M., \& Odell, L. (2012). Making the Implicit Explicit in Assessing Multimodal Composition. Technical Communication Quarterly, 21(1), 1-5.

Lorenzo, G., \& Ittelson, J. (2005, October). Demonstrating and Assessing Student Learning with EPortfolios. Educause Learning Initiative. Retrieved from https://net.educause.edu/ir/library/pdf/eli3003.pdf.

McKee, H., \& DeVoss, D. (2013). Digital Writing Assessment and Evaluation. Computers \& Composition Digital Press. Retrieved June 27, 2016, from http://ccdigitalpress.org/dwae/index.html.

Moran, C., \& Herrington, A. (2013). Seeking Guidance for Assessing Digital Compositions/Composing. In Digital Writing Assessment and Evaluation, edited by Heidi A. McKee and Dànielle Nicole DeVoss. Computers \& Composition Digital Press. Retrieved July 12, 2016, from http://ccdigitalpress.org/dwae/03_moran.html.

Murray, E., Sheets, H., \& Williams, N. (2010). The New Work of Assessment: Evaluating Multimodal Compositions. Computers and Composition Online, Spring 2010. Retrieved from http://www.bgsu.edu/cconline/murray_etal/index.html.

Penrod, D. (2005). Composition in Convergence: The Impact of New Media on Writing Assessment. New York: Routledge.

Poe, M. (2013). Making Digital Writing Assessment Fair for Diverse Writers. In Digital Writing Assessment and Evaluation, edited by Heidi A. McKee and Dànielle Nicole DeVoss. Computers \& Composition Digital Press. Retrieved July 12, 2016, from http://ccdigitalpress.org/dwae/01_poe.html. 
Rosenthal, J. (1996). Qualitative Descriptors of Strength of Association and Effect Size. Journal of Social Service Research, 21(4), 37-59.

Shipka, J. (2009). Negotiating rhetorical, material, methodological, and technical difference: Evaluating multimodal designs. College Composition and Communication, 61(1), 343-366.

Sorapure, M. (2006). Between Modes: Assessing Student New Media Compositions. Kairos: A Journal of Rhetoric, Technology, and Pedagogy. Retrieved June 25, 2016, from http://technorhetoric.net/10.2/coverweb/sorapure/.

The National Writing Project MAP Group. (2013). Developing Domains for Multimodal Writing Assessment: The Language of Evaluation, the Language of Instruction. Elyse Eidman-Aadahl, Kristine.

Turkle, S. (2011). Alone Together: Why We Expect More from Technology and Less From Each Other. New York: Basic Books.

VanKooten, C. (2016). Toward a Rhetorically Sensitive Assessment Model for New Media Composition. In Digital Writing Assessment and Evaluation, edited by Heidi A. McKee and Dànielle

Woodward, H., \& Nanlohy, P. (2010). Digital Portfolios: Fact or Fashion? Assessment \& Evaluation in Higher Education, 29(2), 227-238.

Yancey, K. (2004). Looking for Sources of Coherence in a Fragmented World: Notes toward a New Assessment Design. Computers and Composition, 21(1), 89-102.

Yancey, K., McElroy, S., \& Powers, E. (2013). Composing, Networks, and Electronic Portfolio: Notes toward a Theory of Assessing E-Portfolios. In Digital Writing Assessment and Evaluation, edited by Heidi A. McKee and Dànielle Nicole DeVoss. Computers \& Composition Digital Press. Retrieved July 19, 2016, from http://ccdigitalpress.org/dwae/08_yancey.html.

Zanzucchi, A., \& Truong, M. (2013). Thinking like a Program: How Electronic Portfolio Assessment Shapes Faculty Development Practices. In Digital Writing Assessment and Evaluation, edited by Heidi A. McKee and Dànielle Nicole DeVoss. Retrieved July 22, 2016, from Computers \& Composition Digital Press: http://ccdigitalpress.org/dwae/08_yancey.html. 